\title{
A Comparative Literature Review on Contributions of Social workers in Kenya and Slovakia to Palliative Care Multidisciplinary Team (Review)
}

\section{O. Okech (Victor Otieno Okech), M. Mackinova (Monika Mackinova)}

Comenius University in Bratislava, Faculty of education in Bratislava, Institute of social studies and therapeutic education, SK

\section{E-mail address:}

okech1@uniba.sk

\section{Reprint address:}

Victor Otieno Okech

Comenius University in Bratislava

Soltesovej 4

81108 Bratislava

SK

Suource: Clinical Social Work and Health Intervention

Volume: 8

Issue: 4

Pages: $75-78$

Cited references: 9

\section{Reviewers:}

Roberto Cauda

Institute of Infectious Diseases, Catholic University of the Sacred Heart, Rome, IT

Vitalis Okoth Odero

Catholic university of Eastern Africa, Nairobi, KE

\section{Key words:}

Palliative Care. Hospice care. Healthcare. Multidisciplinary Team. End of Life Care.

\section{Publisher:}

International Society of Applied Preventive Medicine i-gap

CSWHI 2017; 8(4): 75 - 78; DOI 10.22359/cswhi_8_4_09 @ 2017 Clinical Social Work and Health Intervention

\section{Abstract:}

Introduction: Effective Management of terminally ill patients involves a multidisciplinary team. Social Work is one of the professions that contributes to this team. Objective of this review is to compare how Social Workers in Kenya and Slovakia contribute to the palliative care team. 
Methods: A traditional type of literature review was employed in writing this article. It involved search of articles published in online databases such as ProQuest Central, Oxford Journals, Science Direct, Springer Link and Wiley Online Library. Some of the key words used were: Palliative Care and Multidisciplinary Team.

Results: Social Workers in both countries contribute to a multidisciplinary team with slight differences. For instance, Slovak Social Workers focus more on social advocacy such as seeking powers of the attorney to represent their clients in state offices unlike to their counterparts in Kenya who only come into contact with the legal system when summoned by Courts of law.

Conclusion: In both countries, Kenya and Slovakia, Social Workers immensely contribute to the multidisciplinary team which goes a long way in addressing factors that may hamper effectiveness of palliative care.

\section{Introduction}

Cancer is the $3^{\text {rd }}$ leading cause of death and sickness in Kenya after infectious and cardiovascular diseases. It causes $7 \%$ of the total national mortality each year. The leading types of cancer in women are breast and cervical cancers while in men is prostate and oesophageal cancers $(\mathrm{MoH}$, Kenya, 2013; Korir et al, 2015). Most patients in Kenya (over 80\%) have their first cancer diagnosis at an advanced stage of the disease, making curative approach not to be an option in managing it. Factors that contribute to this late diagnosis range from inadequate or long travel distances to diagnostic centers; long waiting time that may run into months before one is seen by an oncologist; prohibitive costs of diagnosis and treatment, to lack of cancer awareness among patients (Malloy et al, 2017; Muttunga et al, 2015; Kimani et al, 2017; MoH, Kenya 2013).

In Slovakia, Cancer is the second leading cause of death after cardiovascular diseases. This rise is attributed to sedentary life and gradual increase in life expectancy witnessed over past few years. Most cancers (70\%) are diagnosed among patients older than 60 years. In Slovakia, Colorectal and prostrate are the leading types of cancers in men; in female breast and colorectal cancer. In addition, 10 years survival rate for cancer are currently at $75 \%$ for children and $59 \%$ for adults (Vilinová et al, 2015; Ferlay et al, 2013).

\section{Methods}

A traditional style of literature review was adopted in writing this article (Green et al. 2006). It involved search of articles published in online databases. Key words that were used in conducting the search were: 'palliative care', 'Hospice care', 'Multidisciplinary team', 'cancer care' and 'palliative social work. The databases used for electronic searches of the literature were (19752017): Ebook Central (ebrary Academic Complete), EBSCO, ProQuest Central, Oxford Journals, Science Direct, Springer Link and Wiley Online Library. Objective of this review was to compare how Social Workers in Kenya and Slovakia contribute to multidisciplinary team involved in providing palliative care to terminally ill patients. 


\section{Roles and Responsibilities of Social Workers}

In working with terminally ill patients, Social Workers strive in helping patients fulfill four kinds of wishes they would like addressed before they die: these wishes are: Social Wish i.e. they don't die in isolation but be surrounded by their closest friends and relatives, wish for their body, i.e. to die a painless death without difficulties, Psychological Wish, i.e. to have reconciled with all their unfinished businesses before their time of death, Spiritual wish, i.e. all their questions answered about life after death (Munn, 2010; Student et al, 2006).

In Kenya, roles and responsibilities of Social Workers in Public palliative and hospice facilities include: conducting group or individual counseling with patients or families whose members have been diagnosed with cancer, reconnecting or reintegrating abandoned patients in the hospital with their relatives, recommending to the hospital administration for bill waivers to those who are not able to pay, connecting patients with resources such as liking patients from needy families with agencies that may help them in buying medical equipment required of them.

In Slovakia, day to day duties of Social Workers in Palliative and Hospice care are:

1. taking social anamnesis, making diagnosis and developing work plan for social therapies;

2. helping clients overcome social, economic or moral barriers that may interfere with success of treatment;

3 . participates in the process of reintegrating patients back into their communities;

4. holding consultations with doctors on duties on how to realize social interventions for the clients;

5. representing clients when they are needed by police, courts or doing paperwork;
6. performing psychotherapies, and

7. working with families, judges/magistrates and probation officers.

\section{Discussion}

Our general findings were that Social Workers in both countries contributes with some slight differences to multidisciplinary teams tasked with responsibilities of providing palliative care to terminally ill patients. Social Workers in Slovakia focus more on advocacy compared to their counterparts in Kenya who only come into contact with the legal system when summoned by the Courts of Law. This difference can be attributed in the legal systems used in both countries i.e. Common Law vs. Civil Law.

\section{Conclusion}

We conclude that there are some slight differences in how Social Workers in Kenya and Slovakia contribute to their multidisciplinary team. This makes it necessary for members of their team to be knowledgeable of cross-cultural practices, especially now that air travel has advanced, making patients able to move from one part of the globe to another in pursuit of medical care. We also conclude that Social Workers bring to the multidisciplinary team particular skills in working with families and children. These skills play key roles in determining outcomes of palliative care.

\section{References}

1. FERLAY J, STELIAROVA-FOUCHER E, LORTET-TIEULENT J, ROSSO S, COEBERGH JWW, COMBER H, FROMAN D, BRAY, F (2013) Cancer Incidence and Mortality Patterns in Europe: Estimates for 40 Countries in 2012. European Journal of Cancer [Online]. 49(6), 1374-1403, [02.12.2017]. doi: 10.1016/j. ejca.2012.12.027. 
2. KIMANI K (2017) Cancer and Palliative Care in Africa. European Journal of Cancer Care [Online]. 26 (1), Special Issue, [07.12.2017]. doi: 10.1111/ecc.12655.

3. KORIR A, OKEROSI N, RONOH, MUTUMA G, PARKIN M (2015) Incidence of Cancer in Nairobi, Kenya (2004-2008). International Journal of Cancer [Online] 137 (9), 2053-2059, [02.12.2017]. doi: 10.1002/ ijc. 29674 .

4. MALLOY P (2017) Providing Palliative Care to Patients with Cancer: Addressing the Needs in Kenya. Asia-Pacific Journal of Oncology Nursing [Online]. 4 (1), 45-49, [21.11.2017]. doi: 10.4103/23475625.199073.

5. MINISTRY OF HEALTH KENYA (M.O.H) KENYA (2013) National Palliative Care Guidelines, Nairobi: Ministry of Health, Kenya [Online] [21.11.2017]. Available at http://kehpca.org/wp-content/uploads/National-Palliative-Care-Guidelines-02.10.pdf.

6. MUNN J (2010) Identifying and Addressing the Psychosocial, Social, Spiritual, and
Existential Issues Affecting Nursing Homes Residents at the End of Life. In: Bern-Klug, M., (edits) Transforming Palliative Care in Nursing Homes: The Social Work Role New York: Columbia University Press, ISBN: 978-0-231-50707-3.

7. MUTTUNGA J, ANAMPIU J, ABDULKADIR AA (2015) Non-Communicable Diseases and Other Health Issues. In: Kenya Demographic Health Survey (KDHS) 2014 [Online] [02.12.2017]. available at: https://hhsprogram.com/pubs/pdf/ fr308/fr308.pdf.

8. STUDENT, ET AL. (2006) Social Work in Hospice and Palliative Care. Praha: $\mathrm{H} \& \mathrm{H}$ Vysehdradska, s.r.o, 36-84s, ISBN: 807319-059-1.

9. VILINOVA K, REPASKA G, NEMETHOVA J (2015) Cancer Mortality and Incidence in Slovakia and their Special Specifics. Proceedings Geobalcanica 2015. [29.11.2017]. doi: 10.18509/GBP.2015.64. 